P.J.J. van Genderen · H.H.D.M. van Vliet - F.J. Prins

D. van de Moesdijk $\cdot$ R. van Strik - F.J. Zijlstra

U. Budde · J.J. Michiels

\title{
Excessive prolongation of the bleeding time by aspirin in essential thrombocythemia is related to a decrease of large von Willebrand factor multimers in plasma
}

Received: 20 April 1997 / Accepted: 8 August 1997

\begin{abstract}
Patients with essential thrombocythemia (ET), who frequently have bleeding complications, may manifest an excessive prolongation of the bleeding time (BT) after ingestion of aspirin (ASA). The reason for this excessive prolongation of the BT is unknown, but it is attributed to qualitative platelet defects. Since patients with ET may also have acquired abnormalities of plasma and platelet von Willebrand factor (vWF), we questioned whether the excessive prolongation of the BT by ASA was related to changes in either plasma or platelet vWF. To that end, we studied BT and plasma and platelet vWF in ten ET patients, ten patients with reactive thrombocytosis ( $\mathrm{RT}$ ), and ten normal individuals, both before and after administration of $500 \mathrm{mg}$ ASA for 7 days. In a second study, the effect of DDAVP infusion on plasma vWF in relation to the BT was studied in ten normal individuals and ten ET patients after treatment with $100 \mathrm{mg}$ ASA for 3 days. In the first study, treatment with ASA resulted in a significant prolongation of the BT in normal subjects, RT patients, and ET patients. However, in five ET patients an excessive ( $>2 \mathrm{SD}$ ) prolongation of the BT by ASA was observed. Although ASA induced no direct changes in either plasma or platelet vWF levels in either normal subjects, RT patients, or ET patients, all five ET patients who showed an excessive prolongation of the BT
\end{abstract}

P.J.J. van Genderen (两) · H.H.D.M. van Vliet · F.J. Prins · D. van de Moesdijk · J.J. Michiels

Departments of Hematology and Internal Medicine II, University Hospital Dijkzigt, Dr. Molewaterplein 40,

3015 GD Rotterdam, The Netherlands

R. van Strik

Institute of Epidemiology and Biostatistics, Erasmus University, Rotterdam, The Netherlands

\section{F.J. Zijlstra}

Institute of Pharmacology, Erasmus University;

Rotterdam, The Netherlands

U. Budde

Blood Transfusion Service, AK Harburg, Hamburg, Germany by ASA had significantly decreased levels of large vWF multimers in plasma. In the second study, infusion with DDAVP resulted in a significant increase in plasma large vWF multimers, paralleled by a normalization of (excessively) prolonged BT. Our data suggest that in ET inhibition of platelet function by ASA in the presence of concurrently decreased levels of large vWF multimers in plasma may have provoked the excessive BT prolongation.

Key words Aspirin - Bleeding time platelets - von Willebrand factor - Essential thrombocythemia · Bleeding

\section{Introduction}

Excessive bleeding time (BT) prolongation and even severe bleeding have been observed after administering aspirin (ASA) to patients with essential thrombocythemia (ET) and polycythemia vera (PV) $[1,3,10,12$, 13]. The reason for the excessive $\mathrm{BT}$ prolongation by ASA is not known, but it is currently attributed to qualitative platelet defects [1]. However, abnormal BT prolongation after ingestion of ASA is also observed in patients without dysfunctional platelets. For instance, the BT after ingestion of ASA has been used to unmask patients with asymptomatic von Willebrand disease [11]. Furthermore, in patients with congenital von Willebrand disease type 3 who lack the ability to synthesize von Willebrand factor (vWF), a normalization of the prolonged BT may be obtained with transfusion of normal platelets after prior cryoprecipitate infusion, suggesting an important role of platelet vWF in plateletvessel wall interactions [6]. Since ET patients may exhibit abnormalities of plasma vWF (in particular, reduction of large vWF multimers) $[3,4,14,16]$, as well as abnormalities of platelet vWF [5], a study was designed to find out whether the excessive BT prolongation after treatment with ASA in ET patients was related to abnormalities of plasma or platelet vWF. 


\section{Patients and methods}

\section{Design}

The study protocol was approved by the local ethics commitee. The first study was designed to identify ET patients with an excessive BT prolongation after ingestion of $500 \mathrm{mg}$ ASA (i.e., prolongation of BT exceeding the mean +2 SD BT of normal individuals after ingestion of ASA) and to investigate the relationship with changes in plasma or platelet vWF. To that end, a cross-sectional comparison of BT, plasma vWF and platelet vWF-related parameters was made between ten ET patients, ten reactive thrombocytosis (RT) patients, and ten control subjects, both before and after treatment with $500 \mathrm{mg}$ ASA for 7 days. The group of RT patients was used as a control group to evaluate changes which might be attributed to an increased platelet count. In a second study, DDAVP (Minrin, Ferring BV, Hoofddorp, The Netherlands) was administered intravenously in a dose of $0.4 \mu \mathrm{g} / \mathrm{kg}$ body wt. to manipulate plasma vWF and its multimeric distribution and to evaluate the response of ASA-induced (excessively) prolonged BT to changes in plasma vWF. For this purpose, ten ET patients and ten control subjects received $100 \mathrm{mg}$ ASA for 3 days before DDAVP infusion to effectively inhibit platelet cyclooxygenase. BT and plasma vWF-related parameters were measured before, and 1 and $6 \mathrm{~h}$ after DDAVP infusion.

\section{Patients}

After giving informed consent, ten asymptomatic patients with ET (six men and four women, ranging in age from 54 to 83 years, median 62 years) and ten patients with RT (five mean and five women, ranging in age from 35 to 88 years, median 63 years) participated in the first study. The diagnosis of ET was based on commonly accepted clinical and laboratory criteria [13]. The underlying disorder associated with RT was pyelonephritis in one, leprosy and iron deficiency in one, psoriasis arthropathica in one, arteriitis temporalis in one and splenectomy (due to gastric carcinoma in two, abdominal trauma in three and idiopathic thrombocytopenia in one) in six cases. Ten asymptomatic ET patients (five men and fivewomen, ranging in age from 21 to 73 years, median 57 years) with a platelet count of $651 \pm 240 \times 10^{9} / 1$ participated in the second study; two of them had also participated in the first study.

\section{Methods}

Platelet counts were determined routinely in whole blood anticoagulated with EDTA. For all studies involving vWF, blood was collected in one-tenth final volume of $3.8 \%$ trisodium citrate solution containing aprotinin, EDTA, and $N$-ethyl maleimide to give final concentrations of $500 \mathrm{KIU} / \mathrm{ml}, 5 \mathrm{mmol} / 1$ and $6 \mathrm{mmol} / 1$, respectively. Ivy BT, plasma von Willebrand factor antigen (vWF:Ag), ristocetin cofactor activity (vWF:RCoF) and collagen binding activity (vWF:CBA) parameters were measured as described previously [14, 15]. Multimeric analysis of plasma and platelet vWF and the quantification of plasma large vWF multimers was performed as reported in detail elsewhere [4]. Platelet vWF was assayed in supernatants of platelet lysates. In brief, platelets were isolated from platelet-rich plasma. This was followed by two washings with PBS-EDTA and lysis with 1/10 (v/v) of $10 \%$ Triton $\mathrm{X}-100$ in the presence of $500 \mathrm{KIU} / \mathrm{ml}$ aprotinin, $5 \mathrm{mmol} / \mathrm{l}$ EDTA and $6 \mathrm{mmol} / \mathrm{l} N$-ethyl maleimide (final concentration), followed by precipitation of cellular fragments by centrifugation $\left(10 \mathrm{~min}\right.$ at $\left.4{ }^{\circ} \mathrm{C} ; 25000 \mathrm{~g}\right)$. VWF:Ag and $\mathrm{VWF}$ :CBA in platelet lysates were measured as described for plasma vWF, apart from a standard curve constructed with $1 \%$ Triton X-100 (final concentration). Malondialdehyde (MDA) production was measured in platelet-rich plasma after stimulation of platelets by arachidonic acid (AA).

\section{Statistics}

Analysis of variance (ANOVA), followed by Student-NewmanKeuls test (SNK test), was used to identify pair-wise significant differences in group means or differences between the post- and pre-ASA treatment values ( $\triangle$ ASA) of normal controls and RT and ET patients. Correlations between Ivy BT (or $\Delta \mathrm{BT}$ ) and plasma or platelet $\mathrm{vWF}$ parameters (or $\triangle \mathrm{ASA}$ ) were analyzed by linear regression and Spearman rank order tests. Paired $t$-tests were used in the first study to analyze the effect of ASA within each patient or control group and in the second study to evaluate the effect of DDAVP within ET patients or normal subjects. In the second study, plasma vWF parameters and BT of ET patients were compared with those of normal individuals by Student's $t$-test. Statistical significance was accepted at $p<0.05$. All data are expressed as mean $\pm \mathrm{SD}$.

\section{Results}

\section{Pre-ASA treatment values}

As shown in Table 1, mean platelet counts were comparable in ET and RT patients, and both were significantly increased as compared with normal subjects (RT vs $\mathrm{N}: p<0.001$; ET vs $\mathrm{N}, p<0.001)$. Plasma vWF:Ag and vWF:CBA levels were significantly higher in RT patients as compared with both ET patients $(p<0.05)$ and normal individuals $(p<0.05)$. In contrast, per-centages of plasma large vWF multimers were higher in normal individuals as compared with both $\mathrm{RT}$ patients $(p<0.01)$ and ET patients $(p<0.01)$, consistent with previous observations $[4,16]$. There were no significant differences in pre-ASA values of Ivy BT, plasma vWF:RCoF, plasma vWF:RCoF/vWF:Ag ratio, plasma vWF:CBA/vWF:Ag ratio, MDA-AA, platelet vWF:Ag and vWF:CBA (data not shown) between ET and RT patients and normal subjects. The multimeric distribution of platelet vWF was normal in all investigated cases, either with or without treatment with ASA (data not shown).

\section{Effect of treatment with ASA}

Treatment with ASA resulted in a significant inhibition of MDA-AA generation, consistent with an effective inhibition of platelet cyclo-oxygenase activity by ASA (data not shown). In both patient groups and controls, Ivy BT was significantly prolonged by ASA (Fig. 1). However, the BT prolongation was significantly more in $\mathrm{ET}$ patients $(\Delta \mathrm{BT} 213 \pm 132 \mathrm{~s})$ as compared with both RT patients $(\Delta \mathrm{BT} 51 \pm 63 \mathrm{~s}, p<0.001)$ and normal subjects $(\Delta \mathrm{BT} 69 \pm 55 \mathrm{~s}, p<0.01)$. In contrast, there were no significant differences between normal subjects, RT patients and ET patients in effects of ASA on either plasma or platelet vWF. In addition, in each patient or control group, no significant correlations were observed between changes in plasma or platelet vWF (or $\triangle \mathrm{ASA}$ ) on one hand and Ivy BT (or $\Delta \mathrm{BT}$ ) on the other hand, indicating that it is rather unlikely that treatment with ASA had caused changes in plasma or 
Table 1 The effect of aspirin (ASA) in Ivy bleeding time, platelet count, and von Willebrand factor-related parameters in plasma in normal individuals, patients with reactive thrombocytosis, and those with essential thrombocythemia. Data are expressed as mean (SD) ( $v v y B T$ Ivy bleeding time, $v W F: A g$ von Willebrand factor antigen, $v W F: R C o F$ ristocetin cofactor activity, $v W F: C B A$ collagen binding activity)

\begin{tabular}{|c|c|c|c|c|c|c|}
\hline & \multicolumn{2}{|c|}{$\begin{array}{l}\text { Normal individuals } \\
(n=10)\end{array}$} & \multicolumn{2}{|c|}{$\begin{array}{l}\text { Reactive thrombocytosis } \\
(n=10)\end{array}$} & \multicolumn{2}{|c|}{$\begin{array}{l}\text { Essential thrombocythemia } \\
(n=10)\end{array}$} \\
\hline & ASA - & $\mathrm{ASA}+$ & ASA - & $\mathrm{ASA}+$ & ASA - & $\mathrm{ASA}+$ \\
\hline $\begin{array}{l}\text { Ivy BT } \\
\text { (s) }\end{array}$ & $149(60)$ & $218(72) * *$ & 177(73) & $228(75)^{*}$ & $178(62)$ & $391(167)^{* * * *}$ \\
\hline $\begin{array}{l}\text { Platelets } \\
\left(\times 10^{9} / 1\right)\end{array}$ & $237(36)$ & $250(40)$ & $800(198)$ & $729(264)$ & $689(243)$ & $794(223)$ \\
\hline $\begin{array}{l}\text { plasma vWF: Ag } \\
\text { (units/ml) }\end{array}$ & $1.36(0.44)$ & $1.38(0.58)$ & $2.57(1.24)$ & $2.31(1.15)$ & $1.52(0.81)$ & $1.23(0.52)$ \\
\hline $\begin{array}{l}\text { plasma vWF:RCoF } \\
\text { (units/ml) }\end{array}$ & $0.98(0.30)$ & $1.15(0.43)$ & $1.48(1.10)$ & $1.48(0.95)$ & $1.15(0.46)$ & $1.06(0.49)$ \\
\hline $\begin{array}{l}\text { plasma vWF:CBA } \\
\text { (units/ml) }\end{array}$ & $1.31(0.42)$ & $1.42(0.71)$ & $2.47(1.19)$ & $2.00(1.06)$ & $1.19(1.11)$ & $0.77(0.50)$ \\
\hline $\begin{array}{l}\mathrm{vWF}: \mathrm{RCoF} / \mathrm{vWF}: \mathrm{Ag} \\
\text { ratio in plasma }\end{array}$ & $0.74(0.16)$ & $0.87(0.25)$ & $0.54(0.24)$ & $0.60(0.13)$ & $0.89(0.47)$ & $0.88(0.38)$ \\
\hline $\begin{array}{l}\text { vWF: } \mathrm{CBA} / \mathrm{vWF}: \mathrm{Ag} \\
\text { ratio in plasma }\end{array}$ & $0.97(0.17)$ & $1.01(0.14)$ & $0.96(0.34)$ & $0.83(0.20)$ & $0.74(0.37)$ & $0.62(0.28)$ \\
\hline $\begin{array}{l}\text { Plasma large vWF } \\
\text { multimers }(\%)\end{array}$ & $23.1(2.5)$ & $22.0(4.3)$ & $16.4(6.3)$ & $17.5(3.7)$ & $16.6(3.4)$ & $14.2(5.9)$ \\
\hline
\end{tabular}

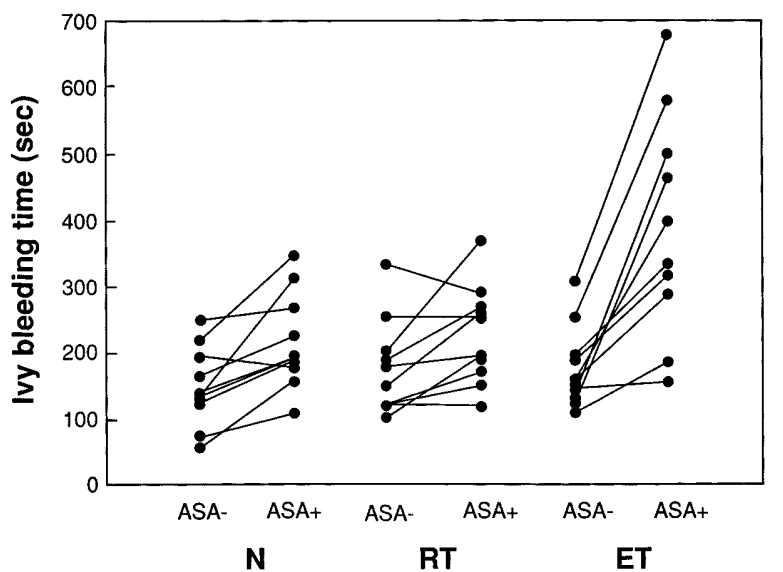

Fig. 1 Ivy BT in 10 patients with essential thrombocythemia (ET), 10 patients with reactive thrombocytosis (RT) and 10 normal subjects $(\mathrm{N})$, before (ASA-) and after treatment $(\mathrm{ASA}+$ ) with $500 \mathrm{mg}$ ASA for 7 days

platelet $\mathrm{vWF}$ resulting in an excessive $\mathrm{BT}$ prolongation. However, as shown in Fig. 2, treatment with ASA unmasked a subgroup of five ET patients who had an excessive BT prolongation after ASA $(524 \pm 109 \mathrm{~s})$ in comparison to ET patients who had a normal prolongation of BT after ASA $(258 \pm 82 \mathrm{~s}, p<0.001)$, RT patients $(228 \pm 5 \mathrm{~s}, \quad p<0.001)$ and normal individuals $(218 \pm 2 \mathrm{~s}, p<0.001)$. All ET patients who showed an excessive ASA-induced BT prolongation had significantly decreased plasma vWF:CBA/vWF:Ag ratios $(n=5 ; 0.42 \pm 0.07)$, as compared with the ratios of ET

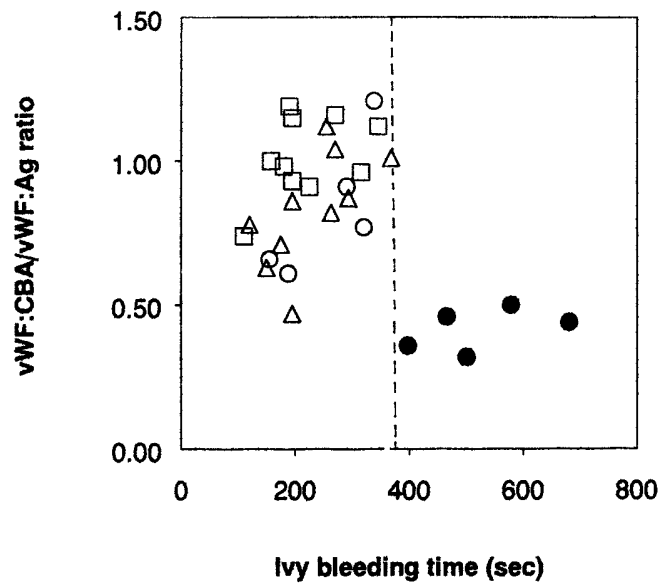

Fig. 2 BT in relation to vWF:CBA/vWF:Ag ratios after administration of $500 \mathrm{mg}$ ASA for 7 days to 10 normal individuals (open squares), 10 RT patients (open triangles) and 10 ET patients. Five ET patients had a normal BT prolongation (open circles) whereas an excessive BT prolongation (closed circles) was noted in $5 \mathrm{ET}$ patients. Broken vertical line denotes the upper limit ( = mean $+2 \mathrm{SD}$ ) of normal BT prolongation after $500 \mathrm{mg}$ ASA. Horizontal line indicates the lower limit for vWF:CBA/vWF:Ag ratios of normal individuals receiving ASA

patients with a normal ASA-induced BT prolongation $(n=5 ; 0.83 \pm 0.24, p<0.001)$, RT patients $(n=10$; $0.83 \pm 0.20, p<0.001)$ and normal subjects $(n=10$; $1.01 \pm 0.14, p<0.001)$. In addition, the five ET patients with an excessive ASA-induced BT prolongation also had significantly decreased percentages of large vWF multimers in plasma $(10.9 \pm 5.7 \%)$ in comparison to ET 
Table 2 Comparison of hemostatic parameters between ET patients with a normal prolongation (BT normal) and excessive prolongation (BT excessive) of the bleeding time after treatment with aspirin. Data are expressed as mean $(\mathrm{SD})$

\begin{tabular}{|c|c|c|c|}
\hline & $\begin{array}{l}\text { BT normal } \\
(n=5)\end{array}$ & $\begin{array}{l}\text { BT excessive } \\
(n=5)\end{array}$ & $\begin{array}{l}p \text {-value } \\
(t \text {-test })\end{array}$ \\
\hline $\begin{array}{l}\text { Ivy BT } \\
\text { (s) }\end{array}$ & $258(82)$ & 524(109) & $p=0.0024^{*}$ \\
\hline $\begin{array}{l}\text { Platelets } \\
\left(\times 10^{9} / 1\right)\end{array}$ & $722(223)$ & $866(223)$ & $p=0.34$ \\
\hline $\begin{array}{l}\text { MDA-AA } \\
\left.\text { (nmol } / 10^{9} \text { plts }\right)\end{array}$ & $0.11(0.17)$ & $0.12(0.19)$ & $p=0.93$ \\
\hline $\begin{array}{l}\text { plasma vWF:Ag } \\
\text { (units/ml) }\end{array}$ & $1.07(0.36)$ & $1.38(0.65)$ & $p=0.39$ \\
\hline $\begin{array}{l}\text { plasma vWF:RCoF } \\
\text { (units/ml) }\end{array}$ & $1.09(0.57)$ & $1.03(0.46)$ & $p=0.86$ \\
\hline $\begin{array}{l}\text { plasma vWF:CBA } \\
\text { (units/ml) }\end{array}$ & $0.95(0.61)$ & $0.59(0.33)$ & $p=0.27$ \\
\hline $\begin{array}{l}\mathrm{vWF}: \mathrm{RCoF} / \mathrm{vWF}: \mathrm{Ag} \\
\text { ratio in plasma }\end{array}$ & $1.00(0.49)$ & $0.75(0.18)$ & $p=0.32$ \\
\hline $\begin{array}{l}\mathrm{vWF}: \mathrm{CBA} / \mathrm{vWF}: \mathrm{Ag} \\
\text { ratio in plasma }\end{array}$ & $0.83(0.24)$ & $0.42(0.07)$ & $p=0.0061^{*}$ \\
\hline $\begin{array}{l}\text { Plasma large vWF } \\
\text { multimers }(\%)\end{array}$ & $17.4(4.3)$ & $10.9(5.7)$ & $p=0.08^{*}$ \\
\hline $\begin{array}{l}\text { Platelet vWF: Ag } \\
\text { (U/10 } 10^{11} \text { plts) }\end{array}$ & 16.1(3.7) & $15.9(7.9)$ & $p=0.96$ \\
\hline $\begin{array}{l}\text { Platelet vWF: CBA } \\
\text { (U/10 } 11 \text { plts) }\end{array}$ & $14.3(5.0)$ & $12.2(10.1)$ & $p=0.69$ \\
\hline $\begin{array}{l}\mathrm{vWF}: \mathrm{CBA} / \mathrm{vWF}: \mathrm{Ag} \\
\text { ratio in platelets }\end{array}$ & $0.88(0.14)$ & $0.70(0.19)$ & $p=0.13$ \\
\hline
\end{tabular}

* Also (highly) significant in 4-group analysis $\mathrm{N}$ vs RT vs ET BT normal vs ET BT excessive patients with a normal BT prolongation $(17.4 \pm 4.3 \%$, $p<0.05)$, RT patients $(17.5 \pm 3.7 \%, p<0.05)$ and normal individuals $(22.0 \pm 4.3 \%, p<0.001)$. These data suggest that inhibition of platelet function by ASA in the presence of decreased levels of large vWF multimers in plasma may have provoked the excessive BT prolongation. Details of the hemostatic parameters of ET patients with and without an excessive ASA-induced BT prolongation are shown in Table 2.

Effect of DDAVP on ASA-induced prolongation of the bleeding time

In a second study, the reduction in large vWF multimers in plasma of ET patients observed in the first study was corrected in vivo by DDAVP infusion, in parallel with BT measurements. Consistent with the findings of the first study, before DDAVP infusion ET patients had significantly lower plasma vWF:CBA/vWF:Ag ratios and significantly longer ASA-induced BT prolongation; four of ten ET patients even fulfilled the criteria for excessive BT prolongation (Fig. 3). After DDAVP infusion vWF:Ag rose from $1.14 \pm 0.31$ to $3.42 \pm 0.82$ units $/ \mathrm{ml}(p<0.0001)$ in normal individuals, and from $1.32 \pm 0.59$ to $2.79 \pm 0.59$ units $/ \mathrm{ml}(p<0.0001)$ in ET patients. In normal individuals, VWF:CBA rose from $1.31 \pm 0.46$ to $5.52 \pm 2.40$ units $/ \mathrm{ml}(p=0.0002)$ after DDAVP, whereas in ET patients $\mathrm{WWF:CBA}$ rose from

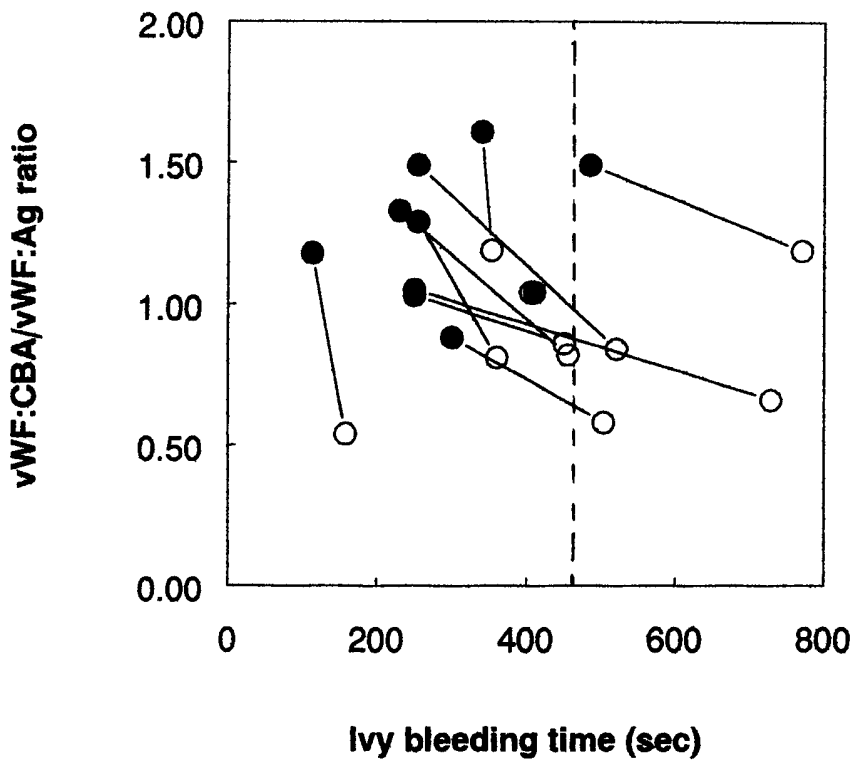

Fig. 3 The effect of DDAVP-induced changes in large vWF multimers in plasma, given as vWF:CBA/vWF:Ag ratio, on ASAinduced prolonged BT in 10 patients with ET. Four of them had an excessive BT prolongation after treatment with $100 \mathrm{mg}$ ASA for 3 days. Open symbols indicate values before administration of DDAVP; closed symbols values 1 hour after administration of DDAVP. Broken vertical line denotes the upper limit of a normal BT prolongation after $100 \mathrm{mg}$ ASA 
Table 3 Effect of DDAVP on ASA-induced prolongation of bleeding time and plasma vWF:CBA/vWF:Ag ratio in ET patients (ET) and control subjects $(\mathrm{N})$. Data are given as mean (SD)

\begin{tabular}{|c|c|c|c|c|c|c|}
\hline & \multicolumn{3}{|c|}{ Ivy bleeding time (s) } & \multicolumn{3}{|c|}{ vWF:CBA/vWF: Ag ratio } \\
\hline & Before & After $1 \mathrm{~h}$ & $p$-value* & Before & After $1 \mathrm{~h}$ & $p$-value \\
\hline $\begin{array}{l}\mathrm{N} \\
(n=10)\end{array}$ & $292(85)$ & $223(67)$ & $p=0.007$ & $1.12(0.15)$ & $1.57(0.41)$ & $p=0.004$ \\
\hline $\begin{array}{l}\mathrm{ET} \\
(n=10)\end{array}$ & $470(179)$ & $289(103)$ & $p=0.004$ & $0.85(0.23)$ & $1.24(0.24)$ & $p=0.0002$ \\
\hline$p$-value $* *$ & $p=0.011$ & $p=0.11$ & & $p=0.006$ & $p=0.04$ & \\
\hline
\end{tabular}

* Paired $t$-test (before vs $1 \mathrm{~h}$ after DDAVP).

** Student's $t$-test ( $\mathrm{N}$ vs ET).

$1.15 \pm 0.61$ to $3.40 \pm 0.72$ units $/ \mathrm{ml} \quad(p<0.0001)$. As shown in Table 3, both ET patients and control subjects showed significant increases of vWF:CBA/vWF:Ag ratios after DDAVP. In parallel with a rise of the plasma vWF:CBA/vWF:Ag ratio, a normalization of BT was observed in all ET patients (Fig. 3), comparable to BT of normal individuals before DDAVP infusion. Six hours after DDAVP infusion a prolongation of BT in ET patients was observed, which again was associated with reduced plasma vWF:CBA/vWF:Ag ratios (data not shown).

\section{Discussion}

The BT is frequently used as the method to evaluate the hemostatic effectiveness of platelets (i.e., primary hemostasis). Multiple mechanisms of platelet activation normally assure the efficiency of primary hemostasis. As a consequence, blockade of one of these pathways, for instance by ASA, results in only a slight disturbance of primary hemostasis, as is evidenced by a slight BT prolongation in normal individuals after ASA. If, however, potential compensatory pathways of primary hemostasis are also affected, for instance by a reduction of large vWF multimers in plasma, excessive BT prolongation and even bleeding may ensue after ingestion of ASA.

Although the population size of ET patients was limited, the present study showed that those patients who had an excessive BT prolongation after ingestion of ASA had a concurrent decrease of large vWF multimers in plasma. The decrease of large vWF multimers in plasma was not attributable to treatment with ASA, since treatment with ASA had no effect on either plasma or platelet vWF. These presented data, however, suggest that the inhibition of platelet function by ASA in the presence of concurrently decreased levels of large vWF multimers in plasma may have provoked the excessive BT prolongation.

The decrease in large vWF multimers in plasma was demonstrated by two independent assays, i.e., direct quantification of large vWF multimers in plasma after SDS gel electrophoresis of vWF and by ELISA-based measurements of the plasma vWF:CBA/vWF:Ag ratio. In a previous study we showed that plasma vWF:CBA/ vWF:Ag ratios are tightly correlated to the percentage of plasma large vWF multimers [16]. The ristocetin cofactor activity, which is usually used to test vWF function in vitro, appeared to be a less sensitive parameter for detecting modest reductions of large vWF multimers in plasma, consistent with previous observations [7, $14,16]$.

The influence of a decreased level of large vWF multimers in plasma on the excessive ASA-induced BT prolongation was stressed by manipulating the plasma levels of large vWF multimers by the infusion of DDAVP. DDAVP releases $\mathrm{vWF}$, including large $\mathrm{vWF}$ multimers, from endothelial storage sites into the circulation [9]. We administered DDAVP to ET patients with an ASA-induced (excessive) BT prolongation; plasma vWF:CBA/vWF:Ag ratios rose significantly $1 \mathrm{~h}$ after DDAVP infusion, indicating a rise of plasma levels of large vWF multimers, in parallel with a significant shortening of the BT, and vice versa $6 \mathrm{~h}$ after DDAVP. These data suggest that an excessive BT prolongation by ASA in ET may be corrected by normalization of plasma levels of large vWF multimers.

In previous studies we found that the reduction of large vWF multimers in plasma in ET is directly related to the number of circulating platelets $[4,14,17]$. The reduction of large vWF multimers in plasma becomes particularly apparent at platelet counts exceeding $1000 \times 10^{9} / 1$, which even may result in a spontaneous bleeding tendency due to an acquired von Willebrand factor deficiency in plasma at higher platelet counts [3, 14]. In accordance with this concept, several epidemiological studies in ET have actually shown an increased incidence of (mucocutaneous) bleeding when the platelet count exceeds the level of $1000 \times 10^{9} / 1[2,8,17]$.

However, as is apparent from the present study, the reduction of large vWF multimers in plasma is also demonstrable, albeit modest, at lower platelet counts, i.e., below $1000 \times 10^{9} / 1$. These patients generally do not suffer from overt bleeding but they may have a latent bleeding tendency. An excessive BT prolongation after treatment with ASA may identify patients at risk for bleeding. Although these data require confirmation in 
appropriate clinical trials, they suggest that the reduction of large vWF multimers in ET may be an important determinant factor for bleeding, in particular when treatment with platelet antiaggregants is considered at increased platelet counts.

Acknowledgement The authors thank Mrs. Janet Stilke and Elke Drewke for their expert technical assistance.

\section{References}

1. Barbui T, Buell M, Cortelazzo S, Viero P, De Gaetano G (1987) Aspirin and the risk of bleeding in patients with thrombocythemia. Am J Med 83:265-268

2. Bellucci S, Janvier M, Tobelem G, Flandrin G, Charpak Y, Berger R, Boiron M (1986) Essential thrombocythemias: clinical, evolutionary and biological data. Cancer 58:2440-2447

3. Budde U, Schaefer G, Mueller N, Egli H, Dent J, Ruggeri Z, Zimmerman T (1984) Acquired von Willebrand's disease in the myeloproliferative syndrome. Blood 64:981-985

4. Budde U, Scharf R, Franke P, Hartmann-Budde K, Dent J, Ruggeri Z (1993) Elevated platelet count as a cause of abnormal von Willebrand factor multimer distribution in plasma. Blood 82:1749-1757

5. Castaman G, Lattuada A, Ruggeri M, Tosetto A, Mannucci P, Rodeghiero F (1995) Platelet von Willebrand factor abnormalities in myeloproliferative syndromes. Am J Hematol 49:289-293

6. Castillo R, Monteagudo J, Escolar G, Ordinas A, Magallon M, Villar J (1993) Hemostatic effect of normal platelet transfusion in severe von Willebrand disease patients. Blood 77:1901-1905

7. Favaloro E, Facey D, Grispo L (1995) Laboratory assessment of von Willebrand factor: use of different assays can influence the diagnosis of von Willebrand's disease, dependent on differing sensitivity to sample preparation and differential recognition of high molecular weight vWF forms. Am J Clin Pathol 104:264-271
8. Fenaux P, Simon M, Caulier M, Lai J, Goudemand J, Bauters F (1990) Clinical course of essential thrombocythemia in 147 cases. Cancer 66:549-556

9. Lethagen S (1994) Desmopressin (DDAVP) and hemostasis. Ann Hematol 69:173-180

10. Leupin L, Beck E, Furian M, Bucher U (1983) Hämostasestörung mit verminderter Aktivität des von Willebrand faktors bei myeloproliferativen Syndromen. Schweiz Med Wochenschr 113:713-716

11. Stuart M, Miller M, Davey F, Wolk J (1979) The post-aspirin bleeding time: a screening test for evaluating haemostatic disorders. Br J Haematol 43:649-659

12. Tartaglia A, Goldberg J, Berk P, Wasserman L (1986) Adverse effects of antiaggregating platelet therapy in the treatment of polycythemia vera. Semin Hematol 23:172-176

13. Van Genderen P, Michiels J (1993) Primary thrombocythemia: diagnosis, clinical manifestations and management. Ann Hematol 67:57-62

14. Van Genderen P, Michiels J, van der Poel - van de Luytgaarde S, van Vliet H (1994) Acquired von Willebrand disease as a cause of recurrent mucocutaneous bleeding in primary thrombocythemia: relationship with platelet count. Ann Hematol 69:81-84

15. Van Genderen P, Vink T, Michiels J, van't Veer M, Sixma J, van Vliet H (1994) Acquired von Willebrand disease caused by an autoantibody selectively inhibiting the binding of von Willebrand factor to collagen. Blood 84:3378-3384

16. Van Genderen P, Budde U, Michiels J, van Strik R, van Vliet $\mathrm{H}$ (1996) The reduction of large von Willebrand factor multimers in plasma in essential thrombocythemia is related to the platelet count. Br J Haematol 93:962-965

17. Van Genderen P, Mulder P, Waleboer M, van de Moesdijk D, Michiels J (1997) Prevention and treatment of thrombotic complications in essential thrombocythemia: efficacy and safety of aspirin. Br J Haematol 97:179-184 